\title{
Hubungan Kecanduan Bermain Video Games Kekerasan dengan Perilaku Agresif pada Murid Laki-laki Kelas IV dan V di SD Negeri 02 Cupak Tangah Pauh Kota Padang
}

\author{
Rivo Armanda Satria ${ }^{1}$, Adnil Edwin Nurdin², Hafni Bachtiar ${ }^{3}$
}

\begin{abstract}
Abstrak
Perilaku agresif adalah perilaku yang bertujuan untuk menyakiti orang lain, untuk mengekspresikan perasaan negatifnya seperti permusuhan untuk mencapai tujuan yang diinginkan. Terdapat 4 aspek agresivitas, yaitu kemarahan, permusuhan, agresi verbal, dan agresi fisik. Salah satu faktor yang diduga mempengaruhi perilaku agresif adalah kebiasaan bermain video games yang mengandung unsur kekerasan. Tujuan penelitian ini adalah untuk mengetahui hubungan perilaku kecanduan bermain video games yang mengandung unsur kekerasan terhadap prilaku agresif pada murid laki-laki kelas IV dan V di SD Negeri 02 Cupak Tangah Pauh Kota Padang Tahun 2014. Penelitian ini menggunakan disain cross sectional study dengan jumlah sampel sebanyak 83 orang murid laki-laki dari kelas IV dan V di SD N 02 Cupak Tangah Pauh. Data dikumpulkan melalui wawancara kepada responden menggunakan kuesioner yang kemudian di analisis dengan uji statistik chi-square dengan derajat kepercayaan 95\% $(0,05)$.Hasil penelitian menunjukkan persentase responden yang memiliki perilaku agresif lebih tinggi pada responden yang mengalami kecanduan bermain video games yang mengandung unsur kekerasan jika dibandingkan dengan responden yang tidak mengalami kecanduan bermain video games yang mengandung unsur kekerasan (67,6\%:20,4\%) dan terdapat hubungan yang bermakna antara kecanduan bermain video games yang mengandung unsur kekerasan dengan perilaku agresif ( $p$-value=0,000).Disarankan bagi pihak sekolah agar memiliki program konseling psikologis anak misalnya dalam bentuk UKESWA (usaha kesehatan jiwa) yang termasuk dalam program UKS (usaha kesehatan sekolah) untuk mendeteksi sejak dini perilaku kecanduan anak terhadap video games yang mengandung unsur kekerasan dan perilaku agresif anak sehingga dapat diberikan bimbingan untuk mengatasi kecanduan dan perilaku agresif tersebut agar tidak berlanjut dan menjadi conduct disorder atau perilaku anti sosial
\end{abstract}

Kata kunci : agresif, kecanduan, video games

\section{Abstract}

Aggressive behavior is a behavior that is intended to harm others to express their negative feelings such as hostility to achieve the desired goal. There are four aspects of aggression, namely anger, hostility, verbal aggression, and physical aggression. One of the factors thought to affect aggressive behavior is a habit of playing violent video games. The objective of this study was to determine the relationship of behavioral addiction playing violent video games toward aggressive behavior in boys elementary school grade IV and V in State Elementary School 02 Cupak Tangah Pauh Padang. This study used a cross sectional study design with total sample of 83 students grade IV and V. Data were collected through interviews with respondents using a questionnaire and then analyzed by chi-square test with $95 \%$ confidence level (0.05). The results obtained the percentage of respondents who have aggressive behavior was higher in respondents who experienced addicted to playing violent video games compared to those who did not experience the addiction of playing violent video games (67.6\%:20.4\%) and there is a significant relationship between addiction playing violence video games with aggressive behavior ( $p$-value $=0.000$ ). It is advisable for the school to have a psychological counseling program for example in the form of UKESWA (mental health efforts) are included in the program UKS (school health unit) for the early detection of children's behavioral addiction to video games and 
aggressive behavior so that the children can be given guidance to overcome the addiction and aggressive behavior in order not to continue and become a conduct disorder or anti-social behavior.

Keywords : addiction, aggressive, video games

Affiliasi penulis : 1.Pendidikan dokter Fakultas Kedokteran Universitas Andalas 2.Bagian IImu Kesehatan Jiwa RSUP Dr. M Djamil Padang 3.Bagian IImu Kesehatan Masyarakat Fakultas Kedokteran Universitas Andalas

Korespondensi : Rivo Armanda Satria, E-mail: rivoarmanda@yahoo.co.id, Telp: 085263518188

\section{PENDAHULUAN}

Video games yang mengandung unsur kekerasan seperti Mortal Combat dan Doom telah populer dikalangan anak-anak dan remaja, sehingga menjadi perhatian khusus bagi orang tua, guru, dan pemerintah. Perhatian semakin besar dalam menyikapi pengaruh bermain video games terhadap perilaku agresif saat terjadinya kasus penembakan 12 orang mahasiswa dan seorang guru oleh Eric Harris dan Dylan Klebold di Columbine High Schoolyang diketahui sebelum terjadinya peristiwa tersebut para pelaku juga memainkan video games berbasis first person shooter.Batelle \& Johnstone menambahkan bahwa diperkirakan terdapat $80 \%$ anak laki-laki berusia antara 8-16 tahun yang mengonsumsi video games. ${ }^{1}$

Perilaku adalah semua kegiatan atau aktivitas manusia, baik yang diamati langsung, maupun yang tidak dapat diamati oleh pihak luar.Menurut Buss dan Perry perilaku agresif adalah keinginan menyakiti orang lain, untuk mengekspresikan perasaan negatifnya seperti permusuhan untuk mencapai tujuan yang diinginkan. Sedangkan Breakwell mendefinisikan bahwa agresivitas itu merupakan suatu bentuk perilaku yang dimaksudkan untuk menyakiti atau merugikan orang lain yang memiliki kemauan bertentangan dengan orang tersebut. ${ }^{2,3}$

Salah satu faktor yang dapat mempengaruhi perilaku agresif adalah kebiasaan bermain video games yang mengandung unsur kekerasan dan mekanisme yang sering dihubungkan dengan perilaku agresif pada penelitian tersebut adalah social learning theory. Pada social learning theory ditarik hipotesisbahwa memainkanvideo games yang agresif, akan menstimulasi prilaku agresif karena anak-anak akan meniru apa yang mereka lihat pada layar saat bermain video games. ${ }^{1}$

Proses pembentukan prilaku, moral dan sikap anak diantaranya berupaimitasi yang berarti peniruan sikap, cara pandang, serta tingkah laku orang lain yang dilakukan dengan sengaja oleh anak dan umumnya anak mulai melakukan imitasi atau peniruan sejak usia 3 tahun, yaitu meniru perilaku orang lain yang ada disekitarnya. Proses lainya yang berperan adalah internalisasi yaitu suatu proses yang merasuk pada diri seseorang (anak) karena pengaruh sosial yang paling mendalam dan paling langgeng dalam kehidupan orang tersebut. ${ }^{4}$

Penelitian sebelumnya menyimpulkan pada usia sekolah, dalam perkembangan kognitifnya anak mampu melakukan fantasi. Fantasi banyak dipengaruhi oleh tontonan yang disaksikan anak.Melalui tontonan, anak-anak mengetahui tokoh jahat dan tokoh baik dan timbul keinginan untuk berperilaku seperti tokoh yang mereka kagumi. Khumas menambahkan bahwa terdapat hubungan antara fantasi agresi dan perilaku agresi pada anakanak. $^{5}$

American Academy of Pediatric mengklaim hubungan antara bemain video games yang mengandung unsur kekerasan dengan perilaku agresif lebih besar jika dibandingkan dengan hubungan antara kebiasaan merokok dan prevalensi penyakit kanker paru, dan media yang menampilkan unsur kekerasan merupakan sebuah faktor yang mempengaruhi setengah dari kejadian pembunuhan setiap tahunnya. ${ }^{6}$

Berdasarkan penelitian tentang perilaku bermain video games murid laki-laki kelas IV dan V SDN 02 Cupak Tangah Pauh, didapatkan bahwa 65 responden $(75,6 \%)$ memiliki tingkat kecanduan ringan terhadap video games dan 21 responden (24,4\%) memiliki tingkat kecanduan sedang. Dari penelitian tersebut juga didapatkan bahwa rata-rata responden dapat memainkan video games lebih dari 3 jam sehari. $^{7}$

Berdasarkan uraian diatas, penulis tertarik untuk meneliti mengenai hubungan kecanduan 
bermain video games yang mengandung unsur kekerasan dengan perilaku agresifpada murid laki-laki kelas IV dan V SD Negeri 02 Cupak Tangah Pauh Kota Padang Tahun 2014.

\section{METODE}

Penelitian ini menggunakan disain cross sectional survey dengan jumlah sampel sebanyak 83 orang murid laki-laki dari kelas IV dan V di SD N 02 Cupak Tangah Pauh Kota Padang. Datayang digunakan berupa data primer yang dikumpulkan melalui wawancara terstruktur menggunakan kuesioner yang kemudian di analisis dengan uji statistik chi-square dengan derajat kepercayaan 95\% $(0,05)$.

\section{HASIL DAN PEMBAHASAN}

a. Karakteristik Responden

Tabel 1. Distribusi Karakteristik Responden Berdasarkan Umur dan Kelas

\begin{tabular}{lll}
\hline \multicolumn{1}{c}{ Perilaku Agresif } & $\mathbf{f}$ & \multicolumn{1}{c}{$\%$} \\
\hline Tidak Agresif & 50 & 60,2 \\
Agresif & 33 & 39,8 \\
\hline Jumlah & 83 & 100
\end{tabular}

Berdasarkan tabel 1 dapat dilihat bahwa dari 83 orang responden diketahui responden terbanyak berada pada rentang usia 10-11 tahun sejumlah 58 orang $(69,9 \%)$. Berdasarkan sebaran kelas dapat diketahui bahwa responden terbanyak duduk di bangku kelas $\mathrm{V} S D$ yaitu sebanyak 43 orang $(51,8 \%)$.

\section{b. Perilaku Kecanduan Bermain Video Games yang Mengandung Unsur Kekerasan}

Tabel 2. Distribusi Responden Berdasarkan Kecanduan Bermain Video Games yang Mengandung Unsur Kekerasan

\begin{tabular}{llc}
\hline Karakteristik Responden & $\mathbf{f}$ & $\%$ \\
\hline Umur & & \\
10-11 tahun & 58 & 69,9 \\
$>11$ tahun & 25 & 30,1 \\
& & \\
Kelas & & \\
IV & 40 & 48,2 \\
V & 43 & 51,8 \\
\hline Jumlah & 83 & 100,0 \\
\hline
\end{tabular}

Berdasarkan tabel 2 dapat diketahui bahwa kurang dari separuh responden mengalami kecanduan bermain video games yang mengandung unsur kekerasan yaitu sebanyak 34 orang (41,0\%). Berdasarkan hasil penelitian pada semua responden yang mengalami kecanduan bermain video games, sebanyak 91,2\% (31 orang) responden mengabaikan kesenangan atau minat lain berupa seringnya lupa makan saat bermain video games dan sebanyak $73,5 \%$ (25 orang) responden mengakui adanya keadaan toleransi berupa keinginan untuk terus menambah waktu dalam bermain video games.

Pada penelitian ini, sebagian besar responden mengakui video games yang sering mereka mainkan merupakan video games dengan latar perkelahian fisik seperti GTA dan Smack Down, serta video games berlatar perang bersenjata seperti Call of Duty, Point Blank, dan Counter Strike. Hal ini sejalan dengan penelitian sebelumnya dalam penelitian tentang dampak bermain game online yang menemukan bahwa sebagian besar murid sekolah dasar lebih memilih memainkan video games berlatar perang bersenjata. $^{8}$

\section{c. Perilaku Agresif}

Tabel 3. Distribusi Frekuensi Perilaku Agresif

\begin{tabular}{lcc}
\hline \multicolumn{1}{c}{ Kecanduan } & $\mathbf{f}$ & $\%$ \\
\hline Tidak Kecanduan & 49 & 59,0 \\
Kecanduan & 34 & 41,0 \\
\hline Jumlah & 83 & 100,0 \\
\hline
\end{tabular}

Berdasarkan tabel 3 dapat diketahui bahwa kurang dari separuh responden memiliki perilaku agresif yaitu sebanyak 33 orang responden (39,8\%).

Berdasarkan penelitian ini diketahui bahwa dari seluruh responden yang memiliki perilaku agresif didapatkan sejumlah 90,9\% (30 orang) responden mengakui menggunakan kekerasan verbal berupa berkata kasar atau berkata kotor jika sedang marah dan sejumlah $84,8 \%$ (28 orang) responden mengakui akan menggunakan kekerasan fisik seperti memukul saat mengalami perselisihan dengan temannya.

Menurut Cavell faktor yang dapat menimbulkan perilaku agresif seorang anak terdiri dari 
faktor biologi, faktor keluarga, sosial-kognitif, peer atau kelompok, akademik, guru-sekolah, dan komunitas. Faktor biologi berhubungan dengan faktor genetik, masa perinatal dan mekanisme biologi.Faktor keluarga misalnnya pola asuh.Faktor sosial-kognitif berhubungan dengan kurang memadainya kemampuan seseorang dalam memproses informasi secara cepat.Berdasarkan penelitian Hartinidiungkapkan bahwa anak mengadopsi perilaku agresinya dari hasil belajar melalui pengamatan anak kepada orang tua (kekerasan yang dilakukan oleh orang tua).Anak dapat meniru semua tingkah laku orang tua yang didapatnya dari kekerasan tersebut.Hal ini sejalan dengan pendapat yang dikemukakan oleh Sears dkk.yaitu salah satu faktor yang dapat memengaruhi perilaku agresif diantaranya berupa imitasi, yaitu semua orang dan anak khususnya mempunyai kecenderungan kuat untuk meniru orang lain. $^{9,10}$

Agresi pada anak juga dapat terjadi akibat pengaruh media massa yang berisi kekerasan (tayangan film). Hasil penelitian Santhoso di Kotamadya Yogyakarta menunjukkan ada korelasi antara minat terhadap film kekerasan dengan kecenderungan perilaku agresi.Demikian juga menurut Santrock yang mengungkapkan bahwa tayangan kekerasan di televisi yang terus menerus ditonton oleh anak-anak menyebabkan meningkatnya agresi pada anak-anak.Faktor lain yang mempengaruhi perilaku agresif dan secara langsung dikaitkan dengan penelitian ini adalah kebiasaan bermain video games yang mengandung unsur kekerasan.,11,12

d. Hubungan Kecanduan Bermain Video Games yang Mengandung Unsur Kekerasan dengan Perilaku Agresif

Tabel 4. Hubungan Kecanduan Bermain Video Games yang Mengandung Unsur Kekerasan dengan Perilaku Agresif

\begin{tabular}{|c|c|c|c|c|c|}
\hline \multirow{3}{*}{$\begin{array}{l}\text { Perilaku } \\
\text { Kecanduan }\end{array}$} & \multicolumn{4}{|c|}{ Perilaku Agresif } & \multirow{3}{*}{$p$} \\
\hline & \multicolumn{2}{|c|}{ Tidak Agresif } & \multicolumn{2}{|c|}{ Agresif } & \\
\hline & $\mathbf{f}$ & $\%$ & $f$ & $\%$ & \\
\hline $\begin{array}{l}\text { Tidak } \\
\text { kecanduan }\end{array}$ & 39 & 79,6 & 10 & 20,4 & 0,000 \\
\hline Kecanduan & 11 & 32,4 & 23 & 67,6 & \\
\hline
\end{tabular}

Berdasarkan tabel 4 dapat dilihat persentase responden yang memiliki perilaku agresif lebih tinggi pada responden yang mengalami kecanduan bermain video games yang mengandung unsur kekerasan jika dibandingkan dengan responden yang tidak mengalami kecanduan bermain video games yang mengandung unsur kekerasan (67,6\%:20,4\%).

Hasil uji Chi-Square didapatkan nilai $p$ value $=0,000(<0,05)$ sehingga secara statsitik dapat disimpulkan bahwa terdapat hubungan bermakna antara kecanduan bermain video games yang mengandung unsur kekerasan dengan perilaku agresif pada murid laki-laki kelas IV dan V di SD Negeri 02 Cupak Tangah Pauh Kota Padang.Hal ini sejalan dengan hasil meta analisis penelitian Sherry yang menyimpulkan adanya hubungan antara bermain video games yang mengandung unsur kekerasan dengan perilaku agresif. ${ }^{1}$

Penelitian sebelumnya oleh Praborini juga menyimpulkan ada hubungan yang signifikan antara kekerasan dalam video games yang dikonsumsi dengan perilaku agresif dengan nilai $p=0,041(<0,05)$ namun dalam penelitiannya, Praborini tidak mengkhususkan penelitian pada kecanduan terhadap video games yang mengandung unsur kekerasan, dan hanya terbatas pada kebiasaan bermain video games yang mengandung unsur kekerasan. Hasil penelitian ini juga terkait dengan social learning theory yang menyatakan bahwa memainkan video games yang agresif, akan menstimulasi prilaku agresif karena anak-anak akan meniru apa yang mereka lihat pada layar saat bermain video games. ${ }^{1.13}$

\section{KESIMPULAN}

Kurang dari separuh murid laki-laki kelas IV dan V di SD Negeri 02 Cupak Tangah Pauh Kota Padang Tahun 2014 mengalami kecanduan bermain video games yang mengandung unsur kekerasan.

Kurang dari separuh murid laki-laki kelas IV dan V di SD Negeri 02 Cupak Tangah Pauh Kota Padang Tahun 2014 memiliki perilaku agresif.

Terdapat hubungan yang bermakna antara Kecanduan bermain video games yang mengandung 
unsur kekerasan dengan perilaku agresif murid lakilaki kelas IV dan V di SD Negeri 02 Cupak Tangah Pauh Kota Padang Tahun 2014.

\section{UCAPAN TERIMA KASIH}

Ucapan terima kasih kepada DR. dr. Adnil Edwin Nurdin, Sp.KJ dan DR. dr. Hafni Bachtiar, MPH yang telah memberikan arahan dan masukan dalam penelitian.

\section{DAFTAR PUSTAKA}

1. Sherry, John L. The Effects of Violent Video games on Aggression A Meta-Analisis. Human Communication Research.2001;27(3):409-31.

2. Notoatmodjo, S. Promosi kesehatan dan ilmu perilaku. Jakarta: Rineka Cipta;2007.

3. Priliantini, A. Hubungan Antara Gaya Manajemen Konflik dengan Perilaku Agresif pada Narapidana Usia Remaja di Lapas Pria Tanggerang. Jurnal Pendidikan Psikologi Konseling.2008; 6:10-20.

4. Sumantri, Mulyani, Nana Syaodih. Perkembangan peserta didik. Jakarta: Universitas Terbuka;2006.

5. Khumas, A. Hastjarjo, D. \& Wimbarti, S. Peran Fantasi Agresi terhadap Perilaku Agresif Anak. Jurnal Psikologi.1997;2:1-9.

6. American Academy of Pediatric Committee on Public Education. Media Violence.
Pediatric.2001:108(5), 1222-6.

7. Amanda, S. Hubungan Pola Asuh Orang Tua Dengan Perilaku Kecanduan Bermain Game Pada Anak Usia Sekolah di SDN 02 Cupak Tangah. Skripsi, Universitas Andalas;2013.

8. Deviandri M, Slamet R, Elvi R.Dampak Game Online Bagi Perilaku Siswa Sekolah Dasar di Kelurahan Gunung Pangilun Kecamatan Padang Utara Kota Padang. Jurnal STKIP PGRI Sumbar.2012;1(3):

9. Suprihatin, Titin.. Agresivitas Anak (Suatu Studi Kasus). Jurnal Psikologi Proyeksi.2011;6(1):5361.

10. Kuniadarmi E.Psikologi perkembangan. Bogor: Penerbit Puspa;2010.

11. Santhoso, F.B.Hubungan antara Minat Terhadap Film Kekerasan di Televisi dan Intensitas Komunikasi Remaja-Orang Tua dengan Kecenderungan Perilaku Agresif Remaja Di Kotamadya Yogyakarta. Tesis,Universitas Gadjah Mada;1994.

12. Santrock. J.W.Adolence : perkembangan remaja. Jakarta: Erlangga;2003.

13. Praborini, N.Hubungan Eksposur Kekerasan dalam Video games dengan Perilaku Agresif Siswa Kelas VIII SMP Negeri 1 Suruh Kabupaten Semarang. Skripsi, FKIP Universitas Kristen Satya Wacana;2011. 